\title{
A construção política da identidade: um desafio feminista à distinção entre político e social
}

\section{The political construction of identity: a feminist challenge to the distinction between the political and the social}

Paulo Eduardo Bodziak Junior

paulo.bodziak@gmail.com

(Universidade de Campinas, São Paulo, Brasil)

Resumo: Se o hábito arendtiano de separar conceitos possibilitou importantes críticas à modernidade e promoveu um novo questionamento sobre 0 sentido da política, ele também possibilitou duras críticas ao pensamento da autora, de machista a nostálgico helênico. Compreender as distinções de modo a evitar compreensões rígidas é o exercício mais adequado para não perder as contribuições de Arendt ao debate político contemporâneo. Nesse sentido, autoras como Bonnie Honig e Hanna Pitkin lançam um desafio interessante às categorias arendtianas, extraindo delas uma possibilidade de leitura muito rica através dos conflitos de formação da identidade. Neste artigo, pretende-se mostrar como uma leitura específica, atitudinal e relacional, pode dar fôlego às distinções de Arendt, atenuando-as, porém sem fazer com que elas percam sua capacidade de traçar características próprias ao político e ao social.

Palavras-chave: Arendt, Identidade, Pitkin, Honig, sociedade.
Abstract: If Arendt's habit of separating concepts allowed her to make important critiques of modernity and promoted a new questioning about the meaning of politics, it also gave space to serious critiques to the author's thought, from sexist to Hellenic nostalgic. In this sense, the most appropriate exercise an interpreter should do in order not to lose Arendt's contributions to the contemporary political debate is to understand these distinctions avoiding a rigid comprehension of them. Authors such as Bonnie Honig and Hanna Pitikin launch interesting challenges to Arendt's categories and make, out of them, a new and appealing reading of the conflicts of identity formation. This paper aims to show how an attitudinal and relational reading can give strength to Arendt's distinctions, insisting on their capacity to trace the differences between social and political but, at the same time, attenuating them.

Keywords: Arendt, Identity, Pitkin, Honig, society. 
Muito provavelmente, o hábito arendtiano de separar conceitos encontra sua expressão mais polêmica na distinção entre político e social e em seu correlato ontológico, a separação entre liberdade e necessidade. Ao afirmar e reafirmar esta tese em diversos textos, como The Human Condition, Reflections on Little Rock e On Revolution, Arendt parece sugerir uma incontornável incompatibilidade entre tais aspectos da vida humana. Entretanto, esta divisão, que parece ser conceitualmente intransponível, pode ser observada como um rico campo de disputa sobre o significado de fenômenos que surgem na esfera pública. É o que buscaremos expor pela análise da formação da identidade e da maneira pela qual essa discussão é enfrentada por autoras feministas. Tais categorias, assim como as de poder, ação e violência, por exemplo, precisam ser lidas como referências significativas que permitam compreender os fenômenos em suas complexidades políticas e sociais. Para demonstrar o que isto significa, sustentaremos que a palavra "social" constitui uma categoria a partir da qual se pode extrair a face política e a face privada dos problemas e dos conflitos sociais. Ao fazer isso, esse texto procura encarar um dos tópicos mais criticados no pensamento arendtiano.

O diálogo com algumas autoras do feminismo - Hanna Pitkin e Bonnie Honig - indica que a separação aparentemente rígida entre político e social em Arendt pode ser superada quando observados os processos de formação de identidade, que mostram que o próprio aparecimento do agente político no espaço público pode ser mobilizado na disputa acerca de suas necessidades. A partir de alguns textos de Hanna Pitkin, poderemos entender o que significa extrair a face política de questões sociais, isto é, perceber a dimensão especificamente política dos elementos envolvidos em uma questão social. Assim, recusando separações rígidas, tentaremos mostrar que as duas dimensões estão sempre relacionadas nas questões públicas. Por isso, denominamos esta leitura atitudinal e relacional. Com Bonnie Honig, André Duarte e Hanna Pitkin, veremos um exercício desta leitura atitudinal e relacional operando na formação da identidade.

Em 1972, quando questionada por sua amiga Mary McCarthy sobre a possibilidade de separar os temas políticos dos sociais em um mundo em que ambos parecem cada vez mais embaralhados, Arendt responde:

Consideremos o problema da moradia. O problema social é certamente uma moradia adequada, mas a questão sobre se esta moradia 
adequada significa integração ou não é certamente uma questão política. Em cada uma destas questões bá uma dupla face, e uma destas faces não deve estar sujeita à discussão. Não deveria haver qualquer debate sobre a questão acerca de se todos devem ter uma moradia decente. ${ }^{1}$

A autora parece estar convencida de que os problemas colocados em apreciação na esfera pública possuem dimensões distintas, demonstrando uma complexidade própria do mundo moderno, que debate publicamente questões que eram, outrora, relegadas ao ambiente privado. Neste sentido, pode-se sugerir que Arendt concebe a distinção entre social e político como um parâmetro que deve ser aplicado no reconhecimento das "faces" que determinado problema público apresenta. ${ }^{2}$ A relação entre social e político, nesse sentido, se assemelha a um embate de forças opostas em um conflito para saber como se organizará o espaço de aparências. ${ }^{3}$ Em outras palavras, trata-se de um

1. ARENDT, H. Sobre Hannah Arendt. Tradução de Adriano Correia. Inquietude, Goiânia, v. 1, n. 2, p. 141, grifo nosso.

2. Deve-se reconhecer aqui que esta passagem não se refere a um trabalho teórico mais sistemático da autora, mas parece frutífero usá-la como ponto de partida para uma leitura proveitosa da questão. Este é um texto de 1972. Portanto, posterior à publicação de todos os textos clássicos da autora publicados durante sua vida. Na realidade, trata-se da transcrição de um debate produzido em Toronto durante um evento em homenagem à sua obra. É importante salientar aqui, embora não haja a oportunidade de polemizar, que Arendt parece bastante "acuada" em relação aos seus interlocutores - todos intelectuais de grande relevância (Richard Bernstein, Macpherson, Hans Jonas, Morgenthau etc). Assim, como era típico de Arendt, embora não tivesse recuado em sua posição teórica estabelecida em suas obras, a autora pareceu ceder pontualmente ao reconhecer que não há em seus textos apontamentos sobre o que poderia ser tema da política no mundo moderno, dado que ela parece vetar os temas ligados à necessidade humana.

3. Compreende-se aqui o "espaço de aparências" como o âmbito próprio de manifestação pública dos fenômenos. Arendt habitualmente não fazia a distinção entre Ser e Aparência, deste modo, repousaria na própria exposição de atos e palavras aos espectadores a existência de um mundo comum aos homens. Como diz a autora: "O espaço de aparência passa a existir sempre que os homens se reúnem na modalidade do discurso e da ação, e portanto precede qualquer constituição formal da esfera pública e as várias formas de governo, isto é, as várias formas possíveis de organização da esfera pública". ARENDT, H. A Condição bumana. Trad. Roberto Raposo. Rio de Janeiro: Forense Universitária, 2008, pp. 211-212. 
conflito no qual, de um lado, se encontra a normalização do comportamento, a reprodução do ciclo vital e a busca incessante pelo consumo e pela geração de abundância e, de outro lado, a espontaneidade e a singularidade, a durabilidade do mundo e a fundação de instituições de liberdade e igualdade. Os elementos que se encontram presentes no domínio público moderno são todos antagônicos. Exatamente por esta complexidade, não se pode cometer o equívoco de leituras como a de O'Sullivan que, ao interpretar os textos de Arendt como uma proposta de retomada das experiências originárias grega e romana da política, afirma que ela fornece uma resposta anacrônica à complexidade da modernidade. ${ }^{4}$

É preciso pensar a distinção entre o social e o político conjugada à própria relação dessas dimensões, sob pena de entender equivocadamente as definições arendtianas como dicotomias estanques. Segundo Duarte,

é preciso caracterizar as inúmeras distinções conceituais propostas por Arendt ao longo de sua obra, pensando-as sempre em seu caráter relacional, isto é, sob a pressuposição de que aquilo que se distingue mantém uma relação intrínseca com aquilo de que se distingue, jamais podendo existir como entidade isolada e absoluta, independentemente de seu outro, de modo que a própria exigência arendtiana de estabelecer distinções implica o reconhecimento de que, na vida política cotidiana, o limite jamais é absoluto, mas sempre tênue e sujeito à contaminação e ao deslocamento. ${ }^{5}$

4. Esta é uma perspectiva de leitura muito consolidada entre críticos de Arendt. Após ser cunhado por Noel O'Sullivan, a expressão "Nostalgia Helênica" de Arendt exprime muito bem a perspectiva de uma linha de alguns comentadores que observam, na teoria arendtiana, um elogio da realidade política grega. Sobre este tema, ver: BENAHABIB, S. Models of Public Space: Hannah Arendt, the Liberal Tradition, and Jürgen Habermas. In: Habermas and the Public Sphere. Craig Calhoun (org.). Cambridge: Cambridge University Press, 1994; HABERMAS, J. Hannah Arendt's Communications Concept of power. Social Research, v. 44, n. 1, 1977, pp. 3-25; e o próprio O'SULLIVAN, N. Hannah Arendt: Hellenic Nostalgia and Industrial Society. In: CRESPIGNY, A.; MINOGUE, K. Contemporary Political philosophers. London: Methuen, 1976, pp. 228-251.

5. DUARTE, A. Poder e Violência no pensamento político de Hannah Arendt: uma reconsideração. In: Sobre a violência. Tradução André Macedo Duarte. Rio de Janeiro: Civilização Brasileira, 2011, p. 134. 
A partir desta leitura, deve-se dar razão à Pitkin, para quem o domínio público não precisa ser protegido de uma determinada matéria ou classe social específica. Para ela, deve-se atentar para "uma atitude particular contra a qual o domínio público deve ser guardado". ${ }^{6}$ Trata-se de compreender que dentro do conflito especificado acima existem duas atitudes distintas diante do mundo, uma pautada pela responsabilidade com a durabilidade do mundo e com a liberdade e, outra, concentrada na geração de riqueza e na normalização do comportamento das pessoas. Como já dissemos, ambas têm sua importância. O problema começa quando uma atitude é cooptada por outra, conduzindo as sociedades à burocratização, à violência, ao conformismo social e à apatia política. Para Pitkin,

Existe uma evidência considerável para tal leitura dos textos. Arendt era consciente de que 'o social' foi trazido para o domínio público menos pelos pobres 'guiados' do que pelos seus líderes bem alimentados, motivados pela pena, e pela burguesia motivada por ansiedade e ganância. E os próprios pobres se tornaram politicamente ativos não quando mais guiados pela necessidade objetiva, mas precisamente quando viram seu sofrimento como contestável $[\ldots]]^{7}$

Pitkin sustenta ainda que Arendt teme acertadamente o embaralhamento de diferentes atitudes (políticas e sociais) no domínio público. Como vimos na passagem acima, em alusão ao processo revolucionário francês, a autora americana concorda com a critica arendtiana que lamentava seu desdobramento em uma erupção violenta. Como Arendt expõe em Sobre a Revolução, a substituição dos processos políticos de construção de acordos pela unanimidade da vontade geral, mobilizada pela compaixão aos miseráveis, retirou do processo revolucionário francês a atitude política própria à esfera pública, entregando-a ao imperativo da necessidade característica da atitude social. Tal mudança constitui fato notável quando verificada sua escalada em detrimento do princípio de ação ${ }^{8}$, concebido por Arendt como

6. PITKIN, H. Justice: On Relating Private and Public. Political Theory, v. 9, n. 3, 1981, p. 342, grifo nosso.

7. Idem, Ibidem.

8. A noção de princípio defendida por Arendt aparece em diversos momentos da obra da autora e tem sua origem na apropriação feita por ela da noção de Princípio de Governo, elaborada por Montesquieu em O Espírito das Leis. O 
um fator mobilizante da política, sempre voltado para a durabilidade do espaço público e para o engendramento de estruturas de poder. Como conclui Pitkin: "o perigo para a vida pública não vem de inserir a questão social, mas de falhar em transformá-la em atividade política, permitindo que ela entre com 'espírito' equivocado" ${ }^{\prime \prime}$. Esta afirmação nos leva a reformular a questão da separação entre social e político. Pautados mais pela sua relação do que pela distinção entre si, devemos agora verificar o que significa "transformar em atividade política" e que atitude este desafio exige.

Em um texto intitulado "Toward an Agonistic Feminism", que sugere uma leitura radical das categorias arendtianas, Bonnie Honig oferece uma alternativa possível para tratar deste tema. Para a comentadora, embora Arendt não considerasse o "problema da mulher" propriamente político, seria possível partir de suas categorias no debate sobre gênero e identidade, desde que uma interpretação performativa e agonística de seus textos fosse adotada ${ }^{10}$. Pretendemos nos apropriar aqui das conclusões de Honig para pensar de que maneira os problemas sociais podem ser abordados como uma atitude política e, mais do que isso, como podem ser transformados em temas políticos.

A radicalização sugerida por Honig consiste em orientar sua leitura pelo problema da formação da identidade. A comentadora espera romper, com isso, os determinismos culturais ou biológicos que fazem as questões de sexo e gênero parecerem um "espaço" fechado aos efeitos da atividade da ação. Neste sentido, haveria a possibilidade de ampliar o sentido de termos como "ação" e "domínio público", dirigindo sua compreensão à atenuação da relação entre público e privado, isto é, posicionando a ação também no domínio privado da vida dos indivíduos. Honig compreende o caráter performático da identidade da mesma maneira como os Revolucionários Americanos

princípio de ação é o que movimenta a ação política, ou seja, é sua motivação. Arendt elenca como possíveis princípios de ação a fama, a honra, a justiça e a solidariedade. Como ela os define, "(...) não consistem em motivos psicológicos. São antes o critério de acordo com o qual todas as ações públicas são julgadas e que articula o conjunto da vida política" ARENDT, H. The Great Tradition: Law and Power. Social Research, v. 74, n. 3, 2007, p. 724.

9. ARENDT, H. The Great Tradition: Law and Power, p. 346.

10. HONIG, B. Toward an Agonistic Feminism. In: Feminist Interpretaions of Hannab Arendt. Pennsylvania: Pennsylvania State University Press, 1995, pp. 135-136 
compreendiam sua Declaração de Independência. Segundo Arendt, as palavras de Jefferson: "Consideramos estas verdades como autoevidentes" ${ }^{111}$ mostram que o poder e a própria autoridade do novo regime estavam sustentados pela performance política dos revolucionários $^{12}$. Embora os revolucionários as considerassem autoevidentes, era a parte do "consideramos" que conferia autoridade ao novo regime estabelecido. A performance diferencia o tipo de autoridade do novo regime, quando observadas as verdades autoevidentes que tradicionalmente dispensam a ação política - um Deus ou uma Lei natural. Para a comentadora, este "consideramos" caracteriza a real fonte de autoridade do novo regime, que é relacionado diretamente à possibilidade de abertura, refundação e reconstituição. Como ela coloca:

Um regime tão favoravelmente disposto à emenda, à ampliação e à refundação deve rejeitar as ancoras fundacionais de Deus, da Lei Natural e verdades autoevidentes porque ela sabe que Deus desafia a ampliação, que Deus é o que não precisa ser ampliado. Deus, lei natural, verdade autoevidente, todos os três são irresistíveis e completos. Estes dispositivos petrificam o poder. Sua reificação da performatividade na constatação fecha os espaços da política e desautoriza o regime pela diminuição de suas possibilidades de refundação e ampliação. ${ }^{13}$

Para a comentadora, a permanente abertura e porosidade da Constituição Americana ao novo são os elementos que devem ser recuperados para se pensar a formação da identidade com vistas à radicalização da interpretação de Arendt.

Se a performatividade é o elemento que impede a "petrificação" de domínios abertos à ação política, Honig avança em sua proposta sustentando que esta performatividade se manifesta na política através de disputas e conflitos, os quais, em uma leitura radicalizada de Arendt, começam com a própria definição daquilo que concerne à política.

Nas duas obras em que Arendt teria definido mais claramente os campos da ação política, A Condição Humana e Sobre a Revolução, ela associa o corpo humano ao campo da necessidade, isto é, o exclui do

11. ARENDT, H. Sobre a Revolução. Trad. Denise Bottman. São Paulo: Companhia das Letras, 2011, p. 248.

12. HONIG, B. Toward an Agonistic Feminism, p. 137

13. Idem, p. 138. 
domínio público. Em A Condição Humana, o foco de Arendt está em apontar para a tendência normalizadora da vida em sociedade, mostrando que sua ascensão é "teorizada em termos de uma usurpação do espaço político pelo behaviorismo, pela sociedade de massa e pela administração 'doméstica' [...Nesta obra], o social ascende, não irrompe à cena"14. Já em sua narrativa sobre os processos revolucionários modernos, ao se debruçar sobre as diferentes características das revoluções Americana, Russa e Francesa, Arendt estaria preocupada em mostrar como a entrada dos pobres fez irromper à cena política francesa as necessidades corporais de uma multidão de pessoas que depositaram, no processo revolucionário, sua esperança de sair da miséria. O tom da obra é definido da seguinte maneira: "Não pode haver discurso, ação, a menos e até que as necessidades violentamente pressionadoras do corpo, irresistíveis de fato, sejam satisfeitas". ${ }^{15}$ A intenção de Honig consiste em mostrar que a definição arendtiana da política está fortemente ancorada em sua compreensão da relação que temos com o corpo, seja pela ruptura violenta em busca de satisfação, seja pela organização do espaço de aparências em torno do ideal de geração da abundância.

À tal compreensão de corpo, ancorada fortemente nas noções de necessidade e determinação biológica, Arendt oporia sua compreensão de indivíduo como agente, revelador da sua identidade através da ação e do discurso. Neste caso, diferente de um corpo unívoco, não-criativo e despótico em suas necessidades, haveria um Eu múltiplo em suas possibilidades de aparecer ao público, que só pode ser identificado no próprio curso de revelação da sua singularidade. Dito de outra forma, não há essência ou natureza precedente à ação. Para Honig,

Esse Eu múltiplo é caracterizado por Arendt como o local de uma luta temporariamente velada cada vez que o Eu age e realiza uma identidade que é produção performativa. A luta é entre o Eu privado e o Eu público, entre a aversão ao risco de ficar em casa e a coragem [...] Este Eu não é sempre um. É o local de uma luta agonística que Arendt (algumas vezes) chama de política ${ }^{16}$.

\footnotetext{
14. Idem, p.139.

15. Idem, ibidem.

16. Idem, p. 141.
} 
Este elemento de conflito enraíza a política na disputa definidora da atitude do agente no domínio público. Trata-se de uma abordagem da relação entre liberdade e necessidade fortemente ancorada na experiência da pólis. Assim, a comentadora questiona o grau de compromisso de Arendt com esta forma de compreender não apenas o mundo, mas o próprio corpo e a gênese da identidade do agente a partir da experiência grega. Afinal, as assimetrias nas cidades gregas não só eram evidentes como também estavam explicitamente ligadas às separações de gênero, raça, origem e idade. Como Arendt colocava,

A pólis diferenciava-se da família pelo fato de somente conhecer 'iguais', ao passo que a família era o centro da mais severa desigualdade [...] Assim, dentro da esfera da família a liberdade não existia, pois o chefe da família, seu dominante, só era considerado livre na medida em que tinha o poder de deixar o lar e ingressar na esfera política, onde todos eram iguais ${ }^{17}$.

Este conflito entre multiplicidade do Eu e unicidade do Corpo era diretamente determinado pela posição de cada um dentro da família. As mulheres, por exemplo, desde seu nascimento não possuíam qualquer possibilidade de multiplicidade. A elas restava a unicidade do corpo e a atividade laboral da casa e do parto. Em suma, estava negada à mulher a possibilidade do agonismo político de constituição diversa e temporária do Eu. Embora tenha apontado a situação na pólis e a condição originária de segregação da mulher para viabilização da política, Arendt não se posicionou criticamente em relação ao tema. Por esse motivo, Hanna Pitkin questiona a existência de um elemento machista no pensamento de Arend $\mathrm{t}^{18}$ e Drucilla Cornell sugere que "a compreensão arendtiana da pólis perpetua a hierarquia de gênero, o que torna seu próprio ideal de política impossível, dando-nos uma concepção da política inseparável da subordinação da mulher ${ }^{\prime \prime 19}$. Ao buscar uma compreensão dos fenômenos políticos orientando-se por distinções tão polêmicas, Arendt se poupou erroneamente do trabalho de recuperar criticamente a experiência originária da separação entre

17. ARENDT, H. A Condição bumana, p. 41.

18. PITKIN, H. Justice: On Relating Private and Public, p. 338

19. CORNELL, D. Transformations: recollective imagination and sexual difference. New York: Routledge, 1993, p. 156. 
público e privado, trazendo consequências indesejáveis (também a ela) para suas análises. Para Duarte,

[...ao] repropor a pertinência da distinção entre as esferas pública e privada, Arendt perdeu de vista exatamente aquele traço perverso da política antiga que teria perdurado no transcurso da história ocidental, e cujas consequências e implicações ainda hoje se fariam sentir. Mas Cornell, certamente exagera ao afirmar que Arendt houvesse comprometido seu próprio ideal político com aquela mesma exclusão, já que a autora, como vimos, não estava preocupada em simplesmente reinstituir ou imitar o modelo antigo da política, o qual já teria sido perdido para sempre ${ }^{20}$.

Embora não haja o compromisso de Arendt com a segregação de gênero ou qualquer outra que seja, é preciso atentar para as consequências desta negligência. Ao não problematizar a experiência originária da separação público/privado - concebida modernamente como político/social - Arendt não tratou de questões que podem limitar ou, simplesmente, inviabilizar tal distinção. Como vimos, é improvável que a autora possuísse um compromisso com a reprodução da desigualdade. No entanto, dada a falha crítica que constatamos, como escapar de possíveis ecos desta negligência na teoria política da autora? Se Honig pretende discutir o problema da formação de identidade radicalizando a leitura de Arendt, ela precisa fazê-lo nos termos teóricos de Arendt, sem que haja ressonância do problema registrado aqui.

Bonnie Honig, compartilhando aspectos da leitura de Hanna Pitkin, afirma que a separação entre social e político pode servir para pontuar diferentes atitudes no espaço público. Como vimos anteriormente, com isso, o problema deixa de ser quais seriam os conteúdos próprios ao domínio público e passa a ser como os tais conteúdos podem ser abordados politicamente, ou não, na esfera pública. Para Honig, isso começa pela própria identidade. Neste sentido, não haveria classes, gêneros ou grupos determinados ontologicamente pelo labor. Arendt não fez esta importante observação, mas Honig e Pitkin o fazem. Embora ainda esteja nos marcos do pensamento arendtiano, a questão a ser feita em um exercício de compreensão muda qualita-

20. DUARTE, A. O pensamento à sombra da ruptura: política e filosofia em Hannab Arendt. São Paulo: Paz e Terra, 2000, pp. 275-276. 
tivamente. Bonnie Honig e Hanna Pitkin nos ajudam a compreender que uma distinção entre conteúdos, além de equivocada, é pouco produtiva para aproveitar as categorias de Arendt. Segundo a leitura de que se trata de uma distinção de atitudes, não se pode definir previamente o que pertence ao domínio público e o que pertence ao privado. Segundo Honig,

[...] a política é protegida de uma variedade de sensibilidades, atitudes, disposições, e abordagens, todas as quais constituem todos os Eus e sujeitos em alguma medida, todos os quais se empenham em uma luta pela dominação do Eu e todos os quais são incompatíveis com a(s) compreensão(ões) de ação que Arendt valoriza. [...] Cada pessoa seria compreendida como a produção performativa de si mesma, não a expressão da essência autentica de uma classe ou de um gênero, mas sempre o produto (sedimentado) de ações, comportamentos, normas, estruturas institucionais de indivíduos, sociedades e politicas culturais ${ }^{21}$.

Assim, dentro da discussão que Honig se propõe a fazer acerca da formação de identidades como um processo de conflito agonístico, não basta acusar tal conflito. Como ela mostra na passagem acima, esta trajetória de conflito está colocada sempre em "estruturas institucionais" diversas e, desta maneira, pode não ser determinada apenas pela ação própria do Eu. A superação da necessidade pela ação política não depende apenas de um ato de "coragem" em detrimento da "aversão ao risco" de sair de casa. Existem elementos que podem impelir o agente para a ação política, como o revolucionário acometido por um processo que bate à porta de sua casa e demanda seu posicionamento ou engajamento favorável ou contrário ao processo em curso. Outros podem retê-lo em subjugo pela necessidade, como um trabalhador(a) preso(a) às tarefas profissionais e domésticas. Drucilla Cornell parece entender a relação entre público e privado nesta mesma direção. A comentadora compartilha a ideia de que o agente político deve prescindir da urgência da necessidade do corpo para que a ação política seja orientada na formação de instituições de liberdade. No entanto, discorda da maneira rígida como esta relação entre liberdade e necessidade se desdobra na leitura corrente de Hannah Arendt. Afinal, um aspecto importante da crítica feminista ao pensamento

21. HONIG, B. Toward an Agonistic Feminism, p.143. 
arendtiano concebe a própria linha que separa político e social como uma batalha política. Nas palavras de Cornell:

Batalhas foram travadas acerca da licença maternidade, do cuidado de crianças e do cuidado coletivo decente do idoso. Estas batalhas não foram apenas sobre emancipação social no domínio da necessidade, foram batalhas políticas travadas sobre a garantia das condições necessárias para assegurar a cidadania das mulheres. Sim, estas foram batalhas políticas sobre o deslocamento da linha entre político e social e mostraram que, sem o deslocamento nesta linha, as mulheres não poderiam ser cidadãs completas. ${ }^{22}$

Nota-se que, na concepção de Honig, a identidade corresponde à própria noção de "atitude" fixada por Pitkin. Para compreender a distinção entre político e social de forma atitudinal e relacional, precisa-se entender que a esfera de aparências em si está em disputa, inclusive nos termos postos por Cornell. Sua formação ocorre em uma teia de relacionamentos ${ }^{23}$ e se resolve exatamente no campo da identidade/atitude do indivíduo. Logicamente, há uma relação recíproca entre o agente e o espaço de aparências, isto é, este condiciona aquele e é, ao mesmo tempo, condicionado por ele.

Da mesma forma que a identidade se estabelece pelo conflito, pode-se perceber que a esfera social, como versão moderna do espaço de aparências, precisa ser vista como palco de libertação das amarras da necessidade. Possibilidade que não resulta mais do "poder pré- político com o qual o chefe da família reinava sobre a família e seus escravos $[\ldots]^{\prime \prime 24}$. Como Cornell expos, as condições assimétricas no domínio social são tema de batalhas políticas relevantes na modernidade. Arendt acertou em pontuar a separação entre social e político que permite chegar neste diagnóstico, mas errou ao ignorar ou subestimar os mecanismos de violência e dominação que mantém classes, gêneros e grupos confinados sob o julgo da necessidade. Embora

22. CORNELL, D. Transformations: recollective imagination and sexual difference, p. 162.

23. Refere-se à compreensão arendtiana de que a ação humana é a única atividade que se realiza sem mediações e exclusivamente entre humanos. As cadeias de ação se constituem como uma "teia de relações" que mantém conectados todos os envolvidos em determinada comunidade. Para mais detalhes, cf. ARENDT, H. A Condição bumana, p. 196.

24. Idem, p. 41. 
forneça elementos importantes para a compreensão e recuperação da política após a experiência totalitária, Arendt não denunciou que o conflito para libertar-se das necessidades ocorre em um ambiente com diversos fatores determinantes que o influenciam e o definem desde o início.

As comentadoras mobilizadas nos ajudam a abandonar uma concepção rígida de distinção entre político e social. Elas mostram que uma abordagem voltada para a relação entre ambas as categorias em detrimento da distinção pura e simples, mais do que possível, é necessária. Isso, contudo, não significa que tal distinção não exista mais. Nas palavras de Honig:

A permeabilidade, inexatidão e ambiguidade de uma distinção entre público e privado, contudo, não são razões para abandoná-la. Ao contrário, sugerem a possibilidade de atenuação [...]. Nós deveríamos ficar com uma noção de ação como um evento, uma ruptura agonística da sequência ordinária de coisas que abre caminho para a novidade e a distinção, um local de resistência ao irresistível, um desafio às regras normalizadoras que buscam constituir, governar e controlar vários comportamentos. E deveríamos, então, estar em posição de identificar locais de ação política em um arranjo muito mais amplo de constatações, oscilando das verdades autoevidentes de Deus, da natureza, da tecnologia e do capital à identidade, ao gênero, à raça e à etnia. ${ }^{25}$

Notoriamente, a proposta de Honig opera a partir das próprias categorias arendtianas, mas, como já dissemos, tem em vista uma radicalização do entendimento da política que a autora defendia. A comentadora ainda reconhece que esta abordagem talvez não fosse aceita por Arendt e pode conduzir a um problema com o qual Arendt estava preocupada e que foi muito bem pontuado por Nancy Fraser, a saber, o fato de que "quando tudo é política, o sentido e especificidade do político desaparece ${ }^{\prime 26}$. Ou seja, se Arendt esteva preocupada em estabelecer distinções, sua preocupação primária era a de recuperar a política, principalmente após o advento dos fenômenos totalitários. Por isso ela recupera a ação entendida como práxis e a esfera política como domínio constituído por/para tal atividade. Evitar que

25. HONIG, B. Toward an Agonistic Feminism, p. 146-147, grifo nosso.

26. FRASER, N. The French Derrideans: Politicizing Deconstruction or Deconstructing the Political?. New German Critique, n. 33, 1984, p. 135. 
a compreensão da política se perca no próprio exercício da ação talvez seja o grande desafio que Arendt se colocou. Ainda mais em uma época em que a relação entre político e social era tão tênue, sujeita à contaminação e ao deslocamento da linha que separa esses domínios. De qualquer forma, "só faz sentido estabelecer distinções para aquilo que se apresenta de maneira intrinsecamente confusa e misturada no mundo político ${ }^{\prime \prime 27}$. Como Honig observa, a separação fixada por Arendt não visa apenas proteger o público da "ascensão perene" ou do "irrompimento urgente" da necessidade, o inverso também é valido. "Arendt domestifica não apenas o comportamento, mas também a ação. Ela dá um lugar para a ação chamar de lar e lhe diz para ficar lá, onde ela pertence. Mas, naturalmente, ela recusa." ${ }^{128}$

A relação entre político e social precisa ser revisitada a fim de evitar o entendimento das categorias de Arendt como critérios que depurem a política dos conflitos e complexidades inerentes ao mundo moderno. No entanto, como se coloca esta perspectiva radical de leitura diante da funcionalização da economia, preocupação fundamental de Arendt em A Condição Humana? Afinal, não poderia tal exercício colocar Arendt na posição de perder sua capacidade de denunciar o caráter pernicioso que a glorificação do trabalho e da abundância trouxeram à política?

Para Aguiar, Arendt está convencida de que o mundo moderno não está caracterizado apenas pela promoção do social ao espaço público, mas pela própria vitória das demandas de urgência da necessidade sobre as instituições de liberdade. A "atitude" predominante já está definida no espaço de aparências organizado em sociedade. Para o comentador:

É como se todos os homens e toda a sociedade, ao privilegiar o econômico, acabassem originando uma situação geral de biologização e escravização, o fim da liberdade necessária para a constituição de um mundo comum. Fracassou a utopia de que a sociedade, ao se engajar exclusivamente na geração de abundância, iria produzir uma situação de liberdade, uma vez que a 'laborização' invadiu também o tempo livre, por exemplo, na forma da industrialização do entretenimento. O labor é, assim, a atividade típica do social [...]

27. DUARTE, A. O pensamento à sombra da ruptura: política e filosofia em Hannab Arendt, p. 135.

28. HONIG, B. Toward an Agonistic Feminism, p.145. 
tudo passou a ser visto em função do progresso, da geração da abundância. ${ }^{29}$

Ademais, Duarte lembra o quão bem vindo é observar que "Arendt escreveu essas linhas durante o boom econômico norte americano dos anos cinquenta, marcado pela glorificação do american way of life $e^{\prime \prime}{ }^{30}$ Indo além, Arendt não baseava suas críticas apenas no processo de exuberância econômica americana. Para ela, tratava-se de constatar a relevância que a geração de riqueza havia alcançado nas esferas públicas de ambos os modelos de sociedade, que à época buscavam se fixar como o mais vantajoso. Para Arendt, ambos os projetos de sociedade, o capitalista e o socialista, objetivavam a realização de algo como uma "ficção comunística" por vias distintas que, por sua vez, também compartilhavam a prática da expropriação. O capitalismo teria começado com um enorme processo de acumulação pela expropriação e até hoje a pratica nas formas mais sofisticadas e suaves de taxação e desvalorização da moeda. O socialismo, por sua vez, levou este processo muito mais adiante, fazendo do estado o proprietário de fábricas, terras e residências. Por isso, "não há alternativa entre capitalismo e socialismo [...], não apenas porque nenhum deles existe em qualquer parte em estado puro, mas porque o que temos aqui são gêmeos, cada um usando um chapéu diferente". ${ }^{31}$ Para Margareth Canovan, após verificar a evolução das ideias de Arendt acerca dos sistemas totalitários,

está claro que sua pintura da 'sociedade' como uma sufocante vida coletiva monolítica de um rebanho de animais humanos tem mais a ver com preconceitos do que com observações [...] uma vez que ela começou a analisar o totalitarismo nos termos da subordinação dos seres humanos a processos quase naturais, ela encontrou desdobramentos análogos em todo seu redor. [Esta abordagem] a levou a observar uniformidade monolítica onde outros observam diversidade e pluralismo e, embora em suas análises seja a unidade biológica da espécie que encontra expressão nesse monismo, a presença

29. AGUIAR, O. Filosofia, Política e Ética em Hannab Arendt. Ijuí: Ed. Unijuí, 2009, p. 247.

30. DUARTE, A. O pensamento à sombra da ruptura: política e filosofia em Hannab Arendt, p. 278.

31. ARENDT, H. Entre o passado e o futuro. Trad. Mauro W. Barbosa. São Paulo: Perspectiva, 2007, p. 184. 
do consumismo conformista [...] deve ter dado plausibilidade a sua avaliação. ${ }^{32}$

Assim, embora Arendt tenha feito uma boa avaliação do avanço do papel que o consumo desempenha nas sociedades contemporâneas, falta-lhe um reconhecimento mais amplo de que seja possível encontrar espaços para a política no mundo moderno. Constatação compartilhada por Duarte e Canovan. Ambos concordam sobre a falta de considerações acerca da "sociedade civil" como um espaço de conflitos e de formação de organizações em torno de questões de gênero, raça, etnia, classe etc. A falta desta expressão e daquilo que ela representa nas análises de Arendt a exporiam ao risco de se tornar prisioneira de suas distinções. De qualquer modo, suas análises possuem mais aspectos positivos para a interpretação do mundo contemporâneo do que ela mesma percebeu. ${ }^{33}$

O problema que esta linha de interpretação suscita diz respeito à própria concepção de sociedade civil. Afinal, não é consenso que este novo espaço estaria organizado em função da liberdade e não da funcionalização da política pela economia ou pela normalização de comportamentos. Aguiar, polemizando a discussão já posta, afirma:

O conceito de sociedade civil que, inicialmente, tanto na sua origem romana (societas civilis), quanto entre os primeiros contratualistas (estado civil), indicava a dimensão política propriamente dita, foi alterado, inclusive como figura jurídica, a partir da ascensão do social nas modernas sociedades burguesas. A partir de então sociedade deixou de significar o campo em que a força e a violência naturais eram limitadas e superadas e passou a traduzir "historicização" e o prolongamento do estado natural, o reino da sobrevivência. Em Hegel e Marx, por exemplo, indica o campo da regulação das relações econômicas, da propriedade, etc. [Como a sociedade civil seria a esfera de legitimação] Isso indica tanto a clivagem entre poder e legitimação como o controle da política a partir dos interesses privados. ${ }^{34}$

32. CANOVAN, M. Hannab Arendt: a reinterpretation of her political thought. Cambridge: Cambridge University Press, 1992, p. 121.

33. DUARTE, A. O pensamento à sombra da ruptura: política e filosofia em Hannab Arendt, p. 283; CANOVAN, M. Hannab Arendt: a reinterpretation of ber political thougbt, pp.121-122.

34. AGUIAR, O. Filosofia, Política e Ética em Hannab Arendt, pp. 250-251. 
Essa alegação de Aguiar é pertinente porque mostra exatamente a ambiguidade inerente à esfera social moderna. Conforme vimos nos comentários passados, se a sociedade civil pode ser tida tanto como espaço próprio de diversidade (mesmo sendo negligenciada por Arendt neste aspecto) quanto como esfera de legitimação e controle a partir de interesses privados, fica evidente a necessidade de traçar distinções que orientem a disputa entre público e privado no âmbito da própria sociedade civil.

Neste sentido, como conclusão deste artigo, vemos a leitura atitudinal e relacional como perspectiva cabível dentro da teoria arendtiana. Afinal, se, por um lado, ela ajuda a trazer as categorias arentianas para compreensão dos conflitos sociais, tal qual pode-se observar na questão de gênero e identidade, atenuando a denunciada rigidez conceitual feita por seus críticos; por outro lado, ela também permite manter a decisiva escolha arendtiana de resgatar parâmetros de significação da ação política, escapando da armadilha moderna de reduzi-la à administração pública das necessidades privadas e de promoção da funcionalização da política pela economia.

\section{Referências}

ARENDT, H. Origins of Totalitarianism. Cleveland and New York: Meridian Books, 1958.

Eichmann em Jerusalém: um relato sobre a banalidade do mal. Tradução de José Rubens Siqueira. São Paulo: Diagrama Texto, 1983.

Crises da República. Tradução de José Volkmann. São Paulo: Perspectiva, 1973.

Homens em tempos sombrios. Tradução de Denise Bottman. São Paulo: Companhia das Letras, 1987.

. A vida do espírito. Tradução de Antônio Abranches, Cesar A.

R. De Almeida e Helena Martins. Rio de Janeiro: Relume-Dumará, 1992.

Lições sobre a filosofia política da Kant. Tradução de André Duarte. Rio de Janeiro: Relume-Dumará, 1993.

Correspondence with Karl Jaspers, 1926-1969. Nova York: Harcourt Brace, 1994.

Rabel Varnbagen: a vida de uma judia alemã na época do romantismo. Trad. Antônio Transito e Gernot Kludasch. Rio de Janeiro: RelumeDumará, 1994. 
Origens do totalitarismo. Tradução Roberto Raposo. São Paulo: Cia das Letras. 2000.

Reflections On Little Rock: preliminary remarks. In: KOHN, J. (org). The Portable Hannab Arendt. New York: Penguin Books, 2000.

A dignidade da política. Antônio Abranches. (org.). Rio de Janeiro: Ediouro. 2002.

Karl Marx and the tradition of Western political Thought. Social Research, v. 69, n. 2, Summer, 2002.

Responsabilidade e Julgamento. KOHN, J. (Org.). Tradução de Rosaura Eichenberg. São Paulo: Companhia das letras, 2004.

Entre o passado e o futuro. Tradução de Mauro W. Barbosa. São Paulo: Perspectiva. 2007.

O que é política?. Tradução de Reinaldo Guarani. Rio de Janeiro: Bertrand Brasil, 2007.

A Condição bumana. Tradução de Roberto Raposo. Rio de Janeiro: Forense Universitária, 2008.

A promessa da política. Tradução de Pedro Jorgensen Jr. Rio de Janeiro: Difel. 2008.

Compreensão: Formação, Exílio e Totalitarismo. Tradução de Denise Bottman. São Paulo: Cia das Letras e Belo Horizonte: UFMG, 2008. Sobre Hannah Arendt. Tradução de Adriano Correia. Inquietude, v. 1, n.2, ago/dez. 2010.

Sobre a revolução. Tradução de Denise Bottman. São Paulo: Companhia das Letras, 2011.

Sobre a violência. Tradução André Macedo Duarte. Rio de Janeiro: Civilização Brasileira, 2011.BENHABIB, S. Critic, Norm and Utopia: A study of the foundations of critical theory. New York: Columbia University Press, 1986.

Hannah Arendt and the redemptive power of narrative. Social research, n. 57, 1990.

Situating the Self. New York: Routledge. 1992.

Models of Public Space: Hannah Arendt, the Liberal Tradition, and Jürgen Habermas. In: CALHOUN, C. (org.). Habermas and the Public Sphere. Cambrigde: Harvard Press, 1994.

The reluctant modernism of Hannab Arendt. New York: Sage Publications, 1996.

CANOVAN, M. The political thought of Hannab Arendt. New York: Harcourt Brace Jovanovzch, 1974. 
The contradictions of Hannah Arendt's political thought. Political Theory. v. 6, n.1, 1978.

On Pitikin's Justice. Political Theory, v. 10, n. 3,1982.

Arendt, Rousseau and Human Plurality in Politics. The Journal of Politics, v. 45, n. 2, 1983.

CORNELL, D. Transformations: recollective imagination and sexual difference. New York: Routledge, 1993.

CORREIA, A. A questão social em Hannah Arendt: apontamentos críticos. Revista Aurora Curitiba, v. 20, n. 26, pp. 101-112, jan-jun. 2008. (org.) Hannab Arendt e a condição bumana. Salvador: Quarteto, 2006.

CLARKE, J. Social Justice and political freedom: revisiting Hannah Arendt's conception of need. Philosopby and Social Criticism, n.19, 1993.

DUARTE, A. O pensamento à sombra da ruptura: política e filosofia em Hannab Arendt. São Paulo: Paz e Terra, 2000.

Poder e Violência no pensamento político de Hannah Arendt: uma reconsideração. In: ARENDT, H. Sobre a violência. Tradução André Macedo Duarte. Rio de Janeiro: Civilização Brasileira, 2011.

FRASER, N. The French Derrideans: Politicizing Deconstruction or Deconstructing the Political? New German Critique, n. 33, 1984, pp. 127-154.

Women, Welfare and Needs Interpratations. Hypatia, v. 2, n. 1, pp 103-121.

HABERMAS, J. Hannah Arendt's Communications Concept of power. Social Research, v. 44, n. 1, 1977, pp. 3-25.

Mudança estrutural na esfera pública. Trad. Flávio Kothe. Rio de Janeiro: Tempo brasileiro, 1984.

HONIG, B. Toward an Agonistic Feminism. In: ___ (org.) Feminist Interpretaions of Hannab Arendt. Pennsylvania: Pennsylvania State University Press, 1995.

PITKIN, H. Justice: On Relating Private and Public. Political Theory. v. 9, n. 3, 1981. pp. 327-352.

Hannab Arendt's Concept of Social. Chicago: The University of Chicago Press, 1998

Conformism, Housekeeping, and the Attack of the Blob: The Origins of Hannah Arendt's Concept of the Social. In: HONIG, B. (org.) Feminist Interpretaions of Hannab Arendt. Pennsylvania: Pennsylvania State University Press, 1995. 
Paulo Eduardo Bodziak Junior

ROUSSEAU. Do Contrato Social. São Paulo: Martin Claret, 2007.

O'SULLIVAN, N. Hannah Arendt: Hellenic Nostalgia and Industrial Society. In CRESPIGNY, A. e MINOGUE, K. (orgs.) Contemporary Political pbilosophers. London: Methuen, 1976, pp. 228-251.

YOUNG-BRUHEL, E. Por amor ao mundo: A vida e a obra de Hannab Arendt. Tradução de Antônio Trânsito. Rio de Janeiro: Relume-Dumará, 1997.

Recebido em 11.09.2013

Aceito em 16.02.2014 